\title{
Incidence of ill-health related job loss and related social and occupational factors. The "unfit for the job" study: a one-year follow-up study of 51,132 workers
}

\author{
Francois-Xavier Lesage ${ }^{\text {Corresp., }}{ }^{1}$, Frederic Dutheil ${ }^{2,3}$, Lode Godderis $^{4}$, Aymeric Divies ${ }^{5}$, Guillaume Choron ${ }^{6}$ \\ 1 Epsylon, Univ Montpellier, Univ Paul Valéry Montpellier 3, CHU, Montpellier, France \\ 2 CNRS, LaPSCo, Physiological and Psychosocial Stress, University Hospital of Clermont-Ferrand, CHU Clermont-Ferrand, Preventive and Occupational \\ Medicine, WittyFit, Université Clermont Auvergne, Clermont-Ferrand, France \\ 3 Faculty of Health, School of Exercise Science, Australian Catholic University, Melbourne, Victoria, Australia \\ 4 Department of Public Health and Primary Care, Environment and Health, Katholieke Universiteit Leuven, Leuven, Belgium \\ 5 Occupational Health Service Ametra, Montpellier, France \\ 6 Univ Montpellier, CHU, Montpellier, France \\ Corresponding Author: Francois-Xavier Lesage \\ Email address: fx-lesage@chu-montpellier.fr
}

Objective The analysis of ill-health related job loss may be a relevant indicator for the prioritisation of actions in the workplace or in the field of public health, as well as a target for health promotion. The aim of this study was to analyse the medical causes, the incidence, and the characteristics of employees medically unfit to do their job. Methods This one-year prospective study included all workers followed by occupational physicians in an occupational health service in the south of France. The incidence of unfitness for work have been grouped according to the main medical causes and analysed. We performed a multivariate analysis in order to adjust the observed risk of job loss based on the age groups, sex, occupation and the activity sectors. Results Seventeen occupational physicians followed up 51,132 workers. The all-cause incidence of being unfit to return to one's job was $7.8 \%$ o $(n=398)$. The two main causes of being unfit for one's job were musculoskeletal disorders $(47.2 \%, \mathrm{n}=188)$ andmental ill-health $(38.4 \%, \mathrm{n}=153)$. Being over 50 years old [Odds ratio (OR) 2.63, 95\% confidence interval (95\% Cl) 2.13-3.25] and being a woman [OR $1.52,95 \% \mathrm{Cl} 1.21-1.91$ ] were associated with the all-cause unfitness, independent of occupation and activity sector. Conclusions Identification of occupational and demographic determinants independently associated with ill-health related job loss may provide significant and cost-effective arguments for health promotion and job loss prevention. 
1 Incidence of ill-health related job loss and related social and

2 occupational factors. The "unfit for the job" study: a one-year

3 follow-up study of 51,132 workers

4

5 François-Xavier Lesage

6 fx-lesage@chu-montpellier.fr

7 affiliation:

8 Epsylon, Univ Montpellier, Univ Paul Valéry Montpellier 3, CHU, Montpellier, France

9

10

11

12

Frederic Dutheil fred_dutheil@yahoo.fr

${ }^{1}$ Université Clermont Auvergne, CNRS, LaPSCo, Physiological and Psychosocial Stress, University Hospital of Clermont-Ferrand, CHU Clermont-Ferrand, Preventive and Occupational Medicine, WittyFit, F-63000 ClermontFerrand, France

${ }^{2}$ Australian Catholic University, Faculty of Health, School of Exercise Science, Melbourne, Victoria 3065 Australia

Lode Godderis lode.godderis@kuleuven.be

KU Leuven, Department of Public Health and Primary Care, Environment and Health,

Kapucijnenvoer 35 Blok D, Box 7001, 3000 Leuven, Belgium

Aymeric Divies aymeric.divies@sistra.pf

Occupational Health Service AMETRA, Montpellier, France

Guillaume Choron - c c guillaume@live.fr 


\section{Incidence of ill-health related job loss and related social and occupational factors. The "unfit for the job" study: a one-year follow-up study of $\mathbf{5 1 , 1 3 2}$ workers}

(3)

Objective The analysis of ill-health related job loss may be a relevant indicator for the prioritisation of actions in the workplace or in the field of public health, as well as a target for health promotion. The aim of this study was to analyse the medical causes, the incidence, and the characteristics of employees medically unfit to do their job.

Methods This one-year prospective study included all workers followed by occupational physicians in an occupational health service in the south of France. The incidence of unfitness for work have been grouped according to the main medical causes and analysed. We performed a multivariate analysis in order to adjust the observed risk of job loss based on the age groups, sex, occupation and the activity sectors.

Results Seventeen occupational physicians followed up 51,132 workers. The allcause incidence of being unfit to return to one's job was $7.8 \%$ ( $(n=398)$. The two main causes of being unfit for one's job were musculoskeletal disorders $(47.2 \%$, $\mathrm{n}=188)$ and mental ill-health $(38.4 \%, \mathrm{n}=153)$. Being over 50 years old [Odds ratio (OR) 2.63, 95\% confidence interval (95\% CI) 2.13-3.25] and being a woman [OR $1.52,95 \%$ CI 1.21-1.91] were associated with the all-cause unfitness, independent of occupation and activity sector.

Conclusions Identification of occupational and demographic determinants independently associated with ill-health related job loss may provide significant and cost-effective arguments for health promotion and job loss prevention. 
The assessment of occupational diseases and their impact is a difficult issue. However, it is important for setting priority actions concerning health and safety at work. Most data concerning these occupational diseases indirectly assesses their incidence or impact. The findings of The

61 Health and Occupation Reporting network (THOR) highlighted the gap between the 62 epidemiological assessment by a network of specialists removed from the workplace (i.e., 63 psychiatrists) and a direct assessment by an occupational physician linked to the workplace (Carder 64 et al., 2009).

The difficulties with assessing the prevalence or the incidence of occupational diseases are (i) the comprehensive identification of the cases, (ii) the reliable notification of work causality concerning multifactorial diseases, and (iii) the knowledge about the population in whom these cases are identified. Over recent years, several occupational disease networks have been developed and data have been collected concerning occupational diseases. Several nationwide networks of clinical specialists have been developed in Europe (Stocks et al., 2015), such as THOR in the UK (McDonald et al., 2006), or the National Occupational Disease Surveillance and Prevention Network (RNV3P) in France (Bonneterre et al., 2010; Faisandier et al., 2011). Another way to assess occupational diseases is to match different data sources. Mustard et al. (2015) matched different and independent data sources: (i) emergency department encounter records, (ii) lost-time workers compensation claims and (iii) representative samples of workers in a national health interview survey (Mustard et al., 2015).

Numerous countries may also have a compensation system for occupational diseases. Data concerning the recognition of occupational diseases are fairly easy to collect by the organisations which pay the compensation. These systems, however, may provide compensation to workers for benign illnesses, such as occupational contact eczema, but compensation may never be claimed 
81 for some frequent and fairly serious diseases, such as work-related depression or burnout

82 syndrome. Consequently, this kind of indicator is a poor representation of the main occupational

83 health problems in a country or a region. Likewise, the analyses of the causes of disability pensions

84 or disability retirements are probably not very suitable for assessing the incidence of occupational

85 diseases. As a result, two of the main difficulties are the collection and use of relevant and reliable 86 indicators.

87 Unfitness ("inaptitude" in French), is the recognition by the occupational physician that a 88 worker's health status is no longer fit for their current job and that they will require a job change.

89 This does not mean that the worker cannot work anymore, but that they can no longer work in their 90 current position. In France, the assessment of the fitness or the unfitness to perform the job is 91 exclusively carried out by the occupational physician (OP) during a medical examination. All paid 92 workers are systematically followed by the OP, either yearly or every two years. Additional 93 specific medical examinations are carried out when a medical problem occurs. Moreover, when a 94 paid worker is on sick leave for one month or more, fitness is systematically assessed by the OP 95 when the worker returns to work (during a medical examination called "the reinstatement visit"). 96 An "unfit for the job" outcome may be pronounced for several reasons, including but not limited 97 to: (i) a change in an employee's health status (e.g., returning to work after recovery from a serious 98 illness or injury), (ii) a medical condition that may limit, reduce or prevent the person from 99 effectively performing a new or current job (e.g., musculoskeletal conditions that limit mobility),

100 (iii) a medical condition that is likely to make it unsafe both for the employee, their co-workers or 101 the public (e.g., driving is essential to the job but the employee is subject to unpredictable and 102 sudden unconsciousness). Each OP follows roughly 3,000 workers (Dutheil et al., 2017). There 103 are currently 5,600 OPs in France who report one of three conditions back to the employer: fit, fit 104 subject to work modification, or unfit for the job. Unfit for the job may lead to being assigned to 105 a new suitable job in the same company, or to the termination of the employment contract due to 106 medical issues. According to a recent study performed in one French region by the General Labour 107 Department of the Ministry of Work, termination of the employment contract is the main 
108 conclusion of an unfitness notification (more than 97\% of cases) (Fernand, 2012).

109 A previous study explored the analysis of the "unfit for the job" determination among 55,026

110 workers by collecting data directly from the medical records of a French occupational health

111 service (Dutheil et al., 2016). The main limitation of this study was that only a univariate analysis

112 was performed. Indeed, the data concerning the followed up workers were non-individual statistics

113 and demographic information in aggregated form (e.g., sex ratio, occupations, average age), not a

114 data frame extracted from the information system. Consequently, the socio-demographics could

115 not be merged with the data frame of unfitness. However, to our knowledge, this is the only study

116 analysing ill-health related job loss.

117

118 The current study aimed to estimate the incidence of unfitness for the job in an occupational

119 health service over a period of one year, and to describe their aetiology and the characteristics of 120 the unfit employees.

121

122

\section{Methods}

124

125 Study design and setting

This follow-up study took place between January $1^{\text {st }} 2014$ and December $31^{\text {st }} 2014$ in the occupational health service in Montpellier (France). Seventeen OPs followed up the employees of this employment area (except for the farming area and the employees in public services).

132 Procedure and participants

134 All of the workers seen in this occupational health service in 2014 were eligible for participation 
135 in the study. General data concerning the workers were extracted from the information system:

136 age, sex, length of service, occupation and industry, fitness or unfitness. Occupation was coded to

137 four digits using the French Occupational Classification (PCS-2003 socio-professional categories)

138 and the industries were coded using the European NACE-2008 nomenclature and aggregated A10

139 international classification. When an OP reported an "unfit for the job", they collected the age,

140 sex, socio-professional group, activity sector, and the diagnostic cause of the unfitness, which was

141 supported by an expert medical opinion (e.g., by a psychiatrist, orthopedic specialist, or a

142 rheumatologist depending on the disease) and the OP's own judgment on the work causality. The

143 duration of the sick leave, the accident at work or the occupational disease recognition procedure,

144 and what became of the employee (occupational reclassification, discharge due to unfitness) were

145 also collected.

146 The subject's fitness for modified work or unfitness with occupational reclassification were not

147 collected as an outcome. Each OP checked the cases of "unfit for the job" using an informatics

148 query at the end of the year and completed the data collection if necessary. All data were

149 anonymously collected. Participants were recruited during annual work medical examinations. No

150 consent was given because anonymous data was used from normal daily clinical practices taken

151 from medical records. The IRB approved the study (2018_IRB-MTP_02-02)

152

153

154 Statistical analysis

155

156 The incidence of unfitness to work was calculated (numerator = number of unfit workers;

157 denominator $=$ number of followed up employees). The statistical analyses were conducted for all

158 causes of unfitness and for the two main groups of pathologies. The relationship between unfitness

159 and the other characteristics was calculated using the crude Odds Ratio (ORc) and its 95\%

160 Confidence Interval (95\% CI). Multivariate analyses were computerised, adjusting for age, sex,

161 occupation and industry, using logistic regression models to provide the adjusted Odds Ratio 
162 (ORa). Statistical analyses were conducted using the $\mathrm{R}$ and epicalc packages.

163

164

165

Results

166

167 Overall, 51,132 employees were followed up by 17 OPs in 2014 and were included in this study.

168 Among them, 398 cases of "unfit for the job" were reported. The overall incidence of "unfit for 169 the job" was $7.8 \%$.

170 Demographics and company characteristics of employees both fit and unfit for the job are

171 presented in Table 1. The mean age of followed up workers was 38.7 years $(\mathrm{SD}=11.8)$. The unfit

172 for the job workers were older $($ mean $=44.4$ years; $\mathrm{SD}=11.8, \mathrm{p}<0.001)$.

173 When all causes were considered, women [ORa 1.52, 95\% CI 1.21-1.91] and workers over 50

174 years old [ORa 2.63, 95\% CI 2.13-3.25] were more frequently unfit for the job (Table 2).

175 Two groups of pathologies caused $85.7 \%$ of the cases of unfitness: musculoskeletal disorders 176 (MSD) (47.2\%) and mental ill-health (38.4\%) (Table 2).

177

178 Most of the cases of unfitness were caused by a MSD. The average age of these workers was 46.0 179 years $(\mathrm{SD}=11.3)$. Among the 188 cases of unfitness caused by a MSD, 32.4\% were recognized as 180 an occupational injury/disease, whereas $64.0 \%$ of these pathologies were estimated to be work 181 related by the OP. The average length of sick leave was significant (13.1 months, SD 12.3). After

182 adjustment, unfitness caused by a MSD was associated with gender [women ORa 1.89, 95\% CI

183 1.35-2.66] and the odds ratio increased with the age groups, notably that of over 50 year olds

184 (Table 2). With regard to the association with the industry, the activity sector for which the number 185 of cases of unfitness was below 10 (manufacturing, construction, and information \& 186 communication) were excluded from the analysis. Moreover, the financial and insurance sectors 187 were aggregated with real estate activities. This aggregated sector was considered as the reference 188 group. All of the other sectors were significantly associated with unfitness, but after adjustment, 
189 only one sector (trade, repair, transportation, accommodation and food services) remained

190 statistically significant [ORa 3.65, 95\% CI 1.32-10.1] (Table 2). The group containing the higher

191 grade white collar workers was less associated [ORa 0.12, 95\% CI 0.02-0.88] with unfitness than

192 the reference group (intermediate occupations and lower supervisors). By contrast, the blue collar

193 workers were highly concerned by unfitness resulting from a MSD [ORa 8.13, 95\% CI 4.52-14.62]

194 compared with the same reference group (Table 2).

195

196 There were 153 declarations of unfitness caused by mental ill-health. Eight cases (5.2\%) were

197 recognized as an occupational injury or an occupational disease by the health insurance.

198 Conversely, the OP estimated that $64.7 \%$ of these diseases were work related. Compared to MSD,

199 the average length of sick leave $(10.3$ months SD 10.5) was lower $(\mathrm{p}<0.05)$ and workers were

200 younger (40.9 years versus 46.0, $\mathrm{p}<0.001)$. Unlike for MSD, age and gender were less associated

201 with mental ill-health related unfitness. Moreover, all occupation groups and activity sectors were

202 concerned (Table 2).

203

204

205

\section{Discussion}

206

207 Data for this study were directly collected by the OP who determined whether the patient was

208 "unfit for the job" or not. Consequently, the job losses and the medical causes are as reliable as

209 possible. Moreover, they are based on a medical examination, supported by an expert medical

210 opinion, and directly extracted from the medical records. Therefore, the data may be considered

211 as reliable and of high quality.

212 The study design allowed information concerning the denominator to be completed. One

213 strength of our design is that the population followed by the OP involved in this study is known

214 and the requested information was extracted directly from the information system. Most of the

215 experts in the network have accurate data concerning the cases (i.e., an occupational disease) but 
216 cannot collect reliable data on the population observed and, consequently, the indicators (e.g.,

217 incidence or associated risk).

218 Determining whether the patient's health is insufficient for the related job, known as "unfit for

219 the job" in France, is exclusively performed by the worker's OP. The number of cases of ill-health

220 related job loss is probably under-evaluated. For example, an employee with anxiety or depression

221 caused by a conflict at work may choose to resign. He could also leave his job with the termination

222 by mutual consent of employment contract. This employee would not be identified as "unfit for

223 the job" although he should be recognized as "unfit for the job". A termination for a medical reason

224 will maintain the unemployment insurance and termination indemnity. This is in the interest of a

225 worker with a medical problem to be determined unfit for their job rather than to resign from the

226 company. However, an employee do not always choose the most interesting way to leave his job

227 in the specific context of mental ill-health caused by a conflict at work. Particularly severe or life-

228 threatening diseases (e.g., most cancers) are probably under-evaluated in this study design, which

229 is probably not appropriately adapted to reliably assess the impact of such pathologies on jobs.

230 Ill-health related job losses and socio-demographic data are easy to extract from the information

231 systems using a simple SQL query. Most of the data are comprehensively coded in the databases

232 of the occupational health services. Moreover, such an epidemiological system is very cost

233 effective and is based on the French occupational health system.

234 One of the major advantages of integrating a denominator (the demographics of all the workers

235 followed up by each OP) is the ability to carry out multivariate analyses. These analyses can

236 provide risk assessments which would allow these risks to be monitored and geographical

237 comparisons to be made in France, or other European countries. This would help to accurately

238 identify ill-health related job losses.

240 The reader should be aware that this study design does not identify work related diseases, neither

241 can it provide a job loads attributable risk, but rather assesses the impact of diseases, work-related

242 or not, on the capacity to maintain the current job. 
243 In our opinion, this must not be considered as a weakness of this study. The mechanisms of the

244 observed pathologies may be partly, completely or not at all work-related. However, it is a delicate 245 issue to determine if a disease is work-related or not (the work causality) for each individual.

246 Diseases are often multifactorial with personal, professional and extra professional components

247 (e.g., mental ill-health). In fact, all data concerning the issue of work causality should be cautiously 248 interpreted. In our study, the outcome is job loss, which is an objective data, rather than the work 249 causality of cases, which requires a judgement. The analysis of the "unfitness for the job", even if 250 it does not allow the work related causality to be determined, allows at-risk groups to be identified 251 and preventative actions to be promoted in order to support the continuation of employment.

252

253

254 Findings

255

256

257

258

259

260

261

262
The global one-year incidence of unfitness in our study was 7.8\%o. A similar study of ill-health related job losses was previously conducted in 2012 in another occupational health service in the east of France (Dutheil et al., 2016). Dutheil et al. found very similar results. They found that the overall one year incidence of job losses was $7.7 \%$. Dutheil's study confirmed the major impact of MSD and mental ill-health on employment. However, the design of this previous study did not allow multivariate analysis (c.f. above). Our study design allowed multivariate analysis because there was a single data frame for fit and unfit workers, and consequently the possibility to adjust the Odds Ratios based on the age groups, sex, occupation and activity sector, which are strongly associated with job losses. Our findings highlight that $85.7 \%$ of ill-health related job losses are related to MSD (47.2\%) and mental ill-health (38.4\%) (Table 2). The high prevalence of job losses related to MSD (Lederer, Weltle \& Weber, 2001; Cherry et al., 2001; Chen, McDonald \& Cherry, 2006)and mental ill-health (Lederer, Weltle \& Weber, 2001; Cherry, Chen \& McDonald, 2006; 
268 Reinhardt, Wahrendorf \& Siegrist, 2013) have been estimated in other countries. Recent data from

269 the THOR-GP network (UK - 2015-2016) estimated that 85\% of self-reported work related ill-

270 health is caused by these two groups of pathologies (Carder et al., 2013), which is similar to our

271 findings. This supports the relevance of "unfit for the job" as an indicator, even if it does not assess

272 the work related incidence of different pathologies. Moreover, the process of rating a pathology as

273 work related is partly subjective and complex, and may lead to a misclassification.

274 The Labour Force Survey (LFS) is the Health and Safety Executive's data source, 275 complemented by other sources such as death certificates and reports from doctors (THOR). It 276 estimated the incidences of work related ill health by stress-anxiety-depression and MSD as 277 690/100,000 workers and 550/100,000 respectively (Health and Safety Executive)

278 . The incidences were higher than the job loss incidence because all of these cases of work279 related ill health did not lead to a classification of "unfit for the job". Stress, anxiety, and depression 280 accounted for $37 \%$ of all work related ill health cases in 2015/2016, and MSD accounted for $41 \%$ 281 of all work related illnesses. These data suggest that mental ill-health and MSD are not only the 282 two main causes of work related diseases, but are also the two main causes of job loss.

283 The underlying employment area could not be representative of France as a whole. That is why 284 we didn't extrapolated our findings, even if a previous study (Dutheil), conducted in another region 285 of French, found a very similar incidence of job loss. Moreover, farming and public service 286 employees (and to a certain extent the construction industry) are followed up by specific health 287 services. Further study is needed to assess the ill health related job losses in these specific activity 288 sectors. However, it would be interesting to extrapolate the data based on socio-professional 289 categories to assess the burden of ill health related job loss in France. 
292 Musculoskeletal disorders

293

294 Our findings highlight the significant increase in the risk of job loss caused by musculoskeletal 295 disorders in workers over 50 years of age. This is a major risk among blue collar workers. It is a 296 particularly worrying situation for people over the age of 50 because the capacity to find a new job 297 in activity sectors where mechanical loads are frequent, and one which is adapted to the potential 298 disability caused by the MSD, may lead to employment problems for the concerned workers and 299 significant social problems. Unfortunately, in our opinion, primary prevention for workplace tasks 300 is probably rarely or insufficiently adapted to the age of the worker. However, maintaining 301 working ability in early old age is essential for sustaining economic growth in Europe (Reinhardt, 302 Wahrendorf \& Siegrist, 2013).

303

304

305 Mental ill-health

306

307 Our findings highlight the huge impact of mental ill-health on job loss. These diseases are invisible 308 in the national data on occupational diseases (e.g., the recognized occupational diseases), notably 309 because it is probably very difficult to determine work causality. For example, according Wong et

310 al., attribution of mental illness to work is thought to involve the consideration of 18 factors (11

311 workplace factors and 7 personal vulnerability factors) (Wong, Poole \& Agius, 2015). In this

312 study, work causality is determined by the OP's own judgement and their knowledge of the 313 workplace. According to French medical insurance data, only a few hundred cases of anxiety or 314 depression are recognized as an occupational disease by the medical insurance.

315 Another important finding is that all workers are at risk. There may be an increased risk for women or older workers, but all socio-professional statuses and activity sectors are impacted by 317 this issue. 
320 Sex

321

322 The results highlight the gender inequalities in the face of job loss due to ill-health (Table 2).

323 Dutheil et al. observed similar univariate risks for job loss due to MSD, mental ill-health and 324 all-causes together for female workers ( $R R=1.51,1.70$ and 1.51 respectively) (9).

325 This gender inequality issue probably needs particular attention. One reason for such inequality 326 may be that a high proportion of women work in activity sectors with high physical or 327 psychological loads. For example, according the National Statistics Institute, women constitute $32887 \%$ of nurses and $62 \%$ of unskilled workers. There are too few cases of job losses in this study 329 (398 cases) to analyse the risks associated with specific occupations matched with sex ratio.

330 However, an extended study (only 17 OPs participated in this study versus over 5,000 OPs in

331 France) could provide more accurate information. A more specific analysis of activity sectors and 332 jobs for the observed population could provide more accurate "indications" concerning these 333 observed data.

Age

Our findings concerning the average age of unfit workers (44.4 years), and the risks of unfitness among workers aged 50 years and older according to the disease groups (Table 2), are similar to the findings of the previous study carried out in 2012 (Dutheil et al., 2016)(9). In this study, the average age of unfit workers was 45.9 years, and the risks of job loss for workers up to the age of

34250 resulting from a MSD, a mental ill-health and all causes together, were 2.92, 1.38, and 2.51

343 respectively. Not surprisingly, our findings highlight the progressive increase of the odds ratios of 344 job loss with the age of the workers, particularly for MSD. 
345 The findings by Alavinia et al., which highlighted the higher relative risk of long term absence due

346 to sickness among those $\geq 50$ years old $(\mathrm{RR}=2.08[1.33 ; 3.24]$; ref $=$ workers $<40$ years old $)$, are

347 consistent with our data (Alavinia et al., 2009). Older workers are a more fragile population, with

348 a higher prevalence of chronic and disabling pathologies leading to long term absence due to

349 sickness and a higher incidence of job loss. Moreover, the combination of a disabling pathology

350 and the loss of a job is a problematic cocktail for professional reintegration. In our opinion, this

351 population is a major priority for primary and secondary preventive actions.

352

353 The use of the international ICD-10 classification for the encoding of pathologies that lead to a

354 determination of unfitness would increase the quality and the processing speed of analyses.

355 Unfortunately, the different information systems in the occupational health services do not provide

356 such a possibility at this time. However, a common system would considerably enhance the

357 epidemiological capacity to analyse ill-health related job losses, and increase the processing speed.

358 It would be appropriate to match our findings with other data sources, such as expert-based

359 networks or observations, as we believe that our data are complementary.

360 The population included in our study was limited (50,000 workers). A more significant

361 population would increase the power of the analysis and would allow a more accurate

362 identification of the sub groups of workers, or specific socio-professional categories, at risk of

363 losing their jobs for medical reasons. It would also provide better information concerning

364 prevention targets or further specific studies.

365

366

\section{Conclusions}

367 French occupational health systems have an important and cost effective epidemiological capacity. The supervisory authority of the occupational health services, the General Labour Department of the Ministry of Work, should consider promoting such an epidemiological approach based on occupational health service data, which could provide useful, accurate, and reliable

371 information in the field of occupational health. Moreover, occupational health information systems 
372 contain accurate and high quality data on workplace analysis, medical records, or

373 sociodemographic data. Several European countries, such as Belgium, could also collect and

374 analyse similar data (Godderis et al., 2015). For these very reasons, an Occupational Health System

375 Data Analysis network should be promoted.

376

377

378 Acknowledgements

379 The authors would like to thank the Occupational physicians who participated in the study, the

380 occupational health service AMETRA-Montpellier, and in particular Mr Bruno Yerriah.

381

382

383

384 References

385

386 Alavinia SM., van den Berg TIJ., van Duivenbooden C., Elders LAM., Burdorf A. 2009. Impact of work-related factors, lifestyle, and work ability on sickness absence among Dutch construction workers. Scandinavian Journal of Work, Environment \& Health 35:325333.

Bonneterre V., Faisandier L., Bicout D., Bernardet C., Piollat J., Ameille J., de Clavière C., Aptel M., Lasfargues G., de Gaudemaris R., RNV3P 2010. Programmed health surveillance and detection of emerging diseases in occupational health: contribution of the French national occupational disease surveillance and prevention network (RNV3P). Occupational and Environmental Medicine 67:178-186. DOI: 10.1136/oem.2008.044610.

396 Carder M., McNamee R., Turner S., Hodgson JT., Holland F., Agius RM. 2013. Time trends in the incidence of work-related mental ill-health and musculoskeletal disorders in the UK. 

100904.

400 Carder M., Turner S., McNamee R., Agius R. 2009. Work-related mental ill-health and "stress" 401 in the UK (2002-05). Occupational Medicine (Oxford, England) 59:539-544. DOI: 10.1093/occmed/kqp117.

403 404 405 406

Chen Y., McDonald JC., Cherry NM. 2006. Incidence and suspected cause of work-related musculoskeletal disorders, United Kingdom, 1996-2001. Occupational Medicine (Oxford, England) 56:406-413. DOI: 10.1093/occmed/kq1040.

Cherry NM., Chen Y., McDonald JC. 2006. Reported incidence and precipitating factors of work-related stress and mental ill-health in the United Kingdom (1996-2001). Occupational Medicine (Oxford, England) 56:414-421. DOI: 10.1093/occmed/kq1041.

Cherry NM., Meyer JD., Chen Y., Holt DL., McDonald JC. 2001. The reported incidence of work-related musculoskeletal disease in the UK: MOSS 1997-2000. Occupational Medicine (Oxford, England) 51:450-455.

Dutheil F., Naughton G., Sindyga P., Lesage F-X. 2016. Ill Health-Related Job Loss: A OneYear Follow-Up of 54,026 Employees. Journal of Occupational and Environmental Medicine 58:918-923. DOI: 10.1097/JOM.0000000000000825.

Dutheil F., Pereira B., Moustafa F., Naughton G., Lesage F-X., Lambert C. 2017. At-risk and intervention thresholds of occupational stress using a visual analogue scale. PloS One 12:e0178948. DOI: 10.1371/journal.pone.0178948.

Faisandier L., Bonneterre V., De Gaudemaris R., Bicout DJ. 2011. Occupational exposome: a network-based approach for characterizing Occupational Health Problems. Journal of Biomedical Informatics 44:545-552. DOI: 10.1016/j.jbi.2011.02.010. 
421 Fernand J. 2012. Trajectoires Inaptitudes - Direccte Bretagne.. Available on

422 http://bretagne.direccte.gouv.fr/trajectoires-inaptitudes

423 Godderis L., Mylle G., Coene M., Verbeek C., Viaene B., Bulterys S., Schouteden M. 2015.

424 Data warehouse for detection of occupational diseases in OHS data. Occupational

425 Medicine (Oxford, England) 65:651-658. DOI: 10.1093/occmed/kqv074.

426

427

428

429

430

431

432

433

434

435

436

437

438

439

440

441

442

443

Health and Safety Executive. Statistics - Work related musculoskeletal disorders. Available on http://www.hse.gov.uk/statistics/causdis/musculoskeletal/index.htm

Lederer P., Weltle D., Weber A. 2001. [Illness-related premature unfitness for work among civil servants in Bavaria - an evaluation in the social medical field]. Gesundheitswesen (Bundesverband Der Arzte Des Offentlichen Gesundheitsdienstes (Germany)) 63:509_ 513. DOI: $10.1055 / \mathrm{s}-2001-16688$.

McDonald JC., Beck MH., Chen Y., Cherry NM. 2006. Incidence by occupation and industry of work-related skin diseases in the United Kingdom, 1996-2001. Occupational Medicine (Oxford, England) 56:398-405. DOI: 10.1093/occmed/kq1039.

Mustard CA., Chambers A., Ibrahim S., Etches J., Smith P. 2015. Time trends in musculoskeletal disorders attributed to work exposures in Ontario using three independent data sources, 2004-2011. Occupational and Environmental Medicine 72:252-257. DOI: 10.1136/oemed-2014-102442.

Reinhardt JD., Wahrendorf M., Siegrist J. 2013. Socioeconomic position, psychosocial work environment and disability in an ageing workforce: a longitudinal analysis of SHARE data from 11 European countries. Occupational and Environmental Medicine 70:156163. DOI: 10.1136/oemed-2012-100924.

Stocks SJ., McNamee R., van der Molen HF., Paris C., Urban P., Campo G., Sauni R., Martínez 
444

445

446

447

448

449

450

451

452

453

454

455

456

457

458

459

460

461

462

463

464

465

466

467

Jarreta B., Valenty M., Godderis L., Miedinger D., Jacquetin P., Gravseth HM., Bonneterre V., Telle-Lamberton M., Bensefa-Colas L., Faye S., Mylle G., Wannag A., Samant Y., Pal T., Scholz-Odermatt S., Papale A., Schouteden M., Colosio C., Mattioli

S., Agius R., Working Group 2; Cost Action IS1002-Monitoring trends in Occupational

Diseases and tracing new and Emerging Risks in a NETwork (MODERNET) 2015.

Trends in incidence of occupational asthma, contact dermatitis, noise-induced hearing loss, carpal tunnel syndrome and upper limb musculoskeletal disorders in European countries from 2000 to 2012. Occupational and Environmental Medicine 72:294-303. DOI: $10.1136 /$ oemed-2014-102534.

Wong MGP., Poole CJM., Agius R. 2015. Attribution of mental illness to work: a Delphi study. Occupational Medicine (Oxford, England) 65:391-397. DOI: 10.1093/occmed/kqv050.

\section{What is new in the paper?}

- In addition to a previous study in France (9), we conducted a multivariate analysis of the causes of job loss in order to adjust the Odds Ratios for the age groups, sex, occupation, and activity sectors strongly associated with job loss.

- We support the recognition of the French occupational health system as an important and cost effective epidemiological tool. 


\section{Table $\mathbf{1}$ (on next page)}

Demographics, company characteristics, and incidence of unfitness for the job 


\begin{tabular}{|c|c|c|c|c|}
\hline & & Employees unfit for the job & Employees fit for the job & $\begin{array}{c}\text { One-year Incidence of unfitness } \\
\% o\end{array}$ \\
\hline Age (years) & $\begin{array}{c}\leq 30 y \\
31-40 y \\
41-50 y \\
51-60 y \\
>60 y\end{array}$ & $\begin{array}{c}50(12.6 \%) \\
91(22.9 \%) \\
98(24.6 \%) \\
124(31.2 \%) \\
35(8.8 \%) \\
\end{array}$ & $\begin{array}{c}15,298(30.2 \%) \\
13,510(26.7 \%) \\
12,180(24.0 \%) \\
8,165(16.1 \%) \\
1,512(3.0 \%) \\
\end{array}$ & $\begin{array}{c}3.26 \\
6.70 \\
7.98 \\
14.96 \\
22.62 \\
\end{array}$ \\
\hline \multirow{2}{*}{ Sex } & Men & $124(31.2 \%)$ & $21,279(42.0 \%)$ & 5.79 \\
\hline & Women & $274(68.8 \%)$ & $29,455(58.0 \%)$ & 9.22 \\
\hline \multirow{4}{*}{ Occupation } & $\begin{array}{l}\text { Higher grade administrative and managerial } \\
\text { occupations, higher grade professionals }\end{array}$ & $24(6.1 \%)$ & $7,650(17.0 \%)$ & 3.13 \\
\hline & Intermediate occupations. Lower supervisors & $65(16.5 \%)$ & $12,220(27.2 \%)$ & 5.29 \\
\hline & $\begin{array}{l}\text { White collar workers. lower services, sales } \\
\text { and clerical occupations }\end{array}$ & $212(53.8 \%)$ & $19,671(43.7 \%)$ & 10.66 \\
\hline & Blue collar workers & $93(23.6 \%)$ & $5,442(12.1 \%)$ & 16.80 \\
\hline \multirow{4}{*}{ Workforce } & $<10$ & $105(26.4 \%)$ & $13,000(25.6 \%)$ & 8.01 \\
\hline & $10-49$ & $138(34.7 \%)$ & $16,102(31.7 \%)$ & 8.50 \\
\hline & $50-249$ & $93(23.4 \%)$ & $14,503(28.6 \%)$ & 6.37 \\
\hline & $\geq 250$ & $57(14.3 \%)$ & $7,129(14.0 \%)$ & 7.93 \\
\hline \multirow{9}{*}{$\begin{array}{l}\text { Activity sectors } \\
\text { (aggregated } A 10 \\
\text { code) }\end{array}$} & Manufacturing (BE) & $4(1.0 \%)$ & $154(0.3 \%)$ & 25.31 \\
\hline & Construction (FZ) & 0 & $515(1.0 \%)$ & 0 \\
\hline & $\begin{array}{l}\text { Wholesale and retail trade, repair of motor } \\
\text { vehicles, transportation and storage, } \\
\text { accommodation and food service activity } \\
\text { (GI) }\end{array}$ & $123(30.9 \%)$ & $14,051(27.7 \%)$ & 8.68 \\
\hline & Information \& communication (JZ) & $2(5.0 \%)$ & $2,306(4.6 \%)$ & 0.87 \\
\hline & Financial \& insurance activities (KZ) & $9(2.3 \%)$ & $2,954(5.8 \%)$ & 3.04 \\
\hline & Real estate activities (LZ) & $13(3.3 \%)$ & $1,350(2.7 \%)$ & 9.54 \\
\hline & $\begin{array}{c}\text { Professional, scientific and technical } \\
\text { activities; administrative and support service } \\
\text { activities (MN) }\end{array}$ & $69(17.3 \%)$ & $9,696(19.1 \%)$ & 7.07 \\
\hline & $\begin{array}{c}\text { Public administration, compulsory social } \\
\text { security; education; human health and social } \\
\text { work activities (OQ) }\end{array}$ & $152(38.2 \%)$ & $14,909(29.4 \%)$ & 10.09 \\
\hline & $\begin{array}{l}\text { Arts, entertainment, repair of household } \\
\text { goods \& other services (RU) }\end{array}$ & $26(6.5 \%)$ & 4,799 (9.5\%) & 5.39 \\
\hline $\begin{array}{l}\text { Overall Sample } \\
\text { (number of workers) }\end{array}$ & & $398(100 \%)$ & $50,734(100 \%)$ & 7.78 \\
\hline
\end{tabular}




\section{Table 2 (on next page)}

Factors associated with unfitness for the job, for the different causes of unfitness: univariate and multivariate analyses

$\mathrm{ORc}=$ crude Odds Ratio; $\mathrm{ORa}=$ odds ratio adjusted on age, sex, occupation and industry; $\mathrm{OR}$ in bold $=$ OR statistically different of 1 . 


\begin{tabular}{|c|c|c|c|c|c|c|c|c|c|c|}
\hline & & \multicolumn{9}{|c|}{ Causes of unfitness for the job } \\
\hline & & ORc $[\mathrm{Cl} 95 \%]$ & ORa[Cl95\%] & $p$ & ORc[CI95\%] & ORa[Cl95\%] & $p$ & $\mathrm{ORc}[\mathrm{Cl} 95 \%]$ & ORa[Cl95\%] & $p$ \\
\hline \multirow{6}{*}{ Age (years) } & $\leq 30 y$ & 1 & 1 & \multirow{4}{*}{$<0.001$} & 1 & 1 & \multirow{4}{*}{$<0.01$} & 1 & 1 & \multirow{4}{*}{$<0.001$} \\
\hline & $31-40 y$ & $1.76[0.97 ; 3.25]$ & $2.37[1.35 ; 4.18]$ & & $2.22[1.34 ; 3.75]$ & $2.23[1.36 ; 3.65]$ & & $2.05[1.46 ; 2.90]$ & $2.43[1.70 ; 3.45]$ & \\
\hline & $41-50 y$ & $3.14[1.83 ; 5.57]$ & $3.81[2.25 ; 6.45]$ & & $1.96[1.16 ; 3.38]$ & $1.90[1.14 ; 3.18]$ & & $2.46[1.74 ; 3.44]$ & $2.64[1.86 ; 3.76]$ & \\
\hline & $51-60 y$ & $6.56[3.94 ; 11.39]$ & $7.35[4.40 ; 12.28]$ & & $2.4[1.38 ; 4.22]$ & $2.26[1.32 ; 3.86]$ & & $4.59[3.31 ; 6.37]$ & $4.75[3.37 ; 6.69]$ & \\
\hline & $\leq 50$ years & $\frac{1}{1}$ & 1 & & & & & $\frac{1}{1}$ & $\frac{1.02[4.00,111.00]}{1}$ & \\
\hline & $>50$ years & $3.65[2.70 ; 4.91]$ & $\mathbf{3 . 4 1}[2.53 ; 4.61]$ & $<0.001$ & $1.50[1.02 ; 2.17]$ & $1.41[0.98 ; 2.04]$ & 0.07 & $2.82[2.29 ; 3.46]$ & $2.63[2.13 ; 3.25]$ & $<0.001$ \\
\hline $\operatorname{Sex}$ & $\begin{array}{c}\text { Men } \\
\text { Women }\end{array}$ & $\begin{array}{c}1 \\
1.64[1.19 ; 2.25]\end{array}$ & $\begin{array}{c}1 \\
\mathbf{1 . 8 9}[1.35 ; 2.66]\end{array}$ & $<0.001$ & $\begin{array}{c}1 \\
1.41[1.00 ; 1.98]\end{array}$ & $\begin{array}{c}1 \\
1.31[0.92 ; 1.88]\end{array}$ & 0.14 & $\begin{array}{c}1 \\
1.48[1.19 ; 1.83]\end{array}$ & $\begin{array}{c}1 \\
\mathbf{1 . 5 2}[1.21 ; 1.91]\end{array}$ & $<0.001$ \\
\hline \multirow{4}{*}{ Occupations } & $\begin{array}{l}\text { Intermediate occupations. Lower } \\
\text { supervisors }\end{array}$ & 1 & 1 & \multirow{4}{*}{$<0.001$} & 1 & 1 & \multirow{4}{*}{0.52} & 1 & 1 & \multirow{4}{*}{$<0.001$} \\
\hline & $\begin{array}{l}\text { Higher grade administrative and } \\
\text { managerial occupations, higher } \\
\text { grade professionals }\end{array}$ & $0.11[0.00 ; 0.69]$ & $0.12[0.02 ; 0.88]$ & & $0.65[0.34 ; 1.16]$ & $0.76[0.43 ; 1.35]$ & & $0.59[0.35 ; 0.96]$ & $0.66[0.41 ; 1.06]$ & \\
\hline & $\begin{array}{l}\text { grade professionals } \\
\text { White collar workers. lower } \\
\text { services, sales and clerical } \\
\text { occupations }\end{array}$ & $4.47[2.59 ; 8.27]$ & $\mathbf{3 . 8 8}[2.25 ; 6.70]$ & & $1.09[0.74 ; 1.64]$ & $1.10[0.74 ; 1.64]$ & & $2.03[1.53 ; 2.72]$ & $1.95[1.47 ; 2.60]$ & \\
\hline & Blue collar workers & $9.43[5.3 ; 17.85]$ & $8.13[4.52 ; 14.62]$ & & $1.02[0.56 ; 1.79]$ & $1.17[0.66 ; 2.07]$ & & $3.21[2.31 ; 4.49]$ & $3.23[2.30 ; 4.54]$ & \\
\hline \multirow{6}{*}{$\begin{array}{l}\text { Activity } \\
\text { sectors } \\
\text { (aggregated } \\
\text { A10 code) }\end{array}$} & Financial \& insurance activities & & & \multirow{6}{*}{$<0.01$} & & & \multirow{6}{*}{0.25} & & & \multirow{6}{*}{0.20} \\
\hline & $\begin{array}{c}(\mathrm{KZ}) \\
\text { Real estate activities (LZ) } \\
n=4326\end{array}$ & 1 & 1 & & 1 & 1 & & 1 & 1 & \\
\hline & $\begin{array}{l}\text { Wholesale and retail trade, repair of } \\
\text { motor vehicles, transportation and } \\
\text { storage, accommodation and food } \\
\text { service activity (GI)) } \\
n=14174\end{array}$ & $5.26[2.00 ; 20.23]$ & $3.65[1.32 ; 10.1]$ & & $1.01[0.53 ; 2.06]$ & $1.05[0.55 ; 2.01]$ & & $1.71[1.08 ; 2.84]$ & $1.45[0.91 ; 2.32]$ & \\
\hline & $\begin{array}{c}n=14174 \\
\text { Professional, scientific and } \\
\text { technical activities; administrative } \\
\text { and support service activities (MN) } \\
n=9765\end{array}$ & $4.22[1.52 ; 16.28]$ & $2.36[0.83 ; 6.71]$ & & $0.75[0.36 ; 1.62]$ & $0.69[0.34 ; 1.39]$ & & $1.39[0.85 ; 2.37]$ & $1.01[0.61 ; 1.65]$ & \\
\hline & $\begin{array}{c}\text { Public administration, compulsory } \\
\text { social security; education; human } \\
\text { health and social work activities } \\
(\mathrm{OQ}) \\
n=15061\end{array}$ & $4.33[1.60 ; 16.42]$ & $2.33[0.84 ; 6.44]$ & & $1.38[0.75 ; 2.73]$ & $1.16[0.63 ; 2.12]$ & & $1.99[1.27 ; 3.28]]$ & $1.35[0.86 ; 2.13]$ & \\
\hline & $\begin{array}{l}\text { Arts, entertainment, repair of } \\
\text { household goods \& other services } \\
(R U) n=4825\end{array}$ & $2.91[0.90 ; 12.28]$ & $1.99[0.64 ; 6.13]$ & & $0.76[0.31 ; 1.84]$ & $0.76[0.34 ; 1.70]$ & & $1.06[0.58 ; 1.97]$ & $0.85[0.48 ; 1.51]$ & \\
\hline
\end{tabular}

